\title{
A Psicologia Social e 0 trânsito
}

$O$ professor Reinier J. A. Rozestraten, do Departamento de Psicologia e Educação da Faculdade de Filosofia, Ciências e Letras de Ribeirão Preto, é um dos estudiosos de Psicologia do Trânsito no Brasil.

A respeito do uso dos psicotécnicos, fez as seguintes afirmaç̌es na Revista Psicologia e Trânsito:

"Para mostrar como a situação é encarada na maioria dos países europeus, transcrevo aqui um parágrafo de uma carta da pesquisadora em Psicologia do Trânsito, A. Lightburn, da Universidade de Nottingham, na Inglaterra dirigida à comissão do Conselho Federal de Psicologia: ' $O$ uso dos testes psicológicos para selecionar motoristas tem sido objeto de estudo da Organização Mundial de Saúde. Eles chegaram à conclusão de que aqueles testes têm apenas um lugar muito limitado não porque as condições psicológicas não fossem importantes, mas porque não foi possível organizar uma bateria de testes psicológicos de aplicação prática razoável que poderia predizer quais os motoristas de alto risco com algum grau aceitável de certeza. Além disto, não parece justificável numa base de custo/benefício, e parece também extremamente impopular em relação à população de motoristas, especialmente em países que dão muito valor à liberdade do indivíduo.' Portanto, questiona-se também se as autoridades têm o direito de devassar a personalidade de um cidadão simplesmente porque ele quer dirigir um carro. Praticamente todos os países da Europa aceitaram as conclusões do Simpósio de Roma. Nestes países, o direito de dirigir é comum a todos; os exames teóricos e práticos são mais apertados, e somente quando os erros e os acidentes mostram que existem problemas na pessoa e que eles prejudi-

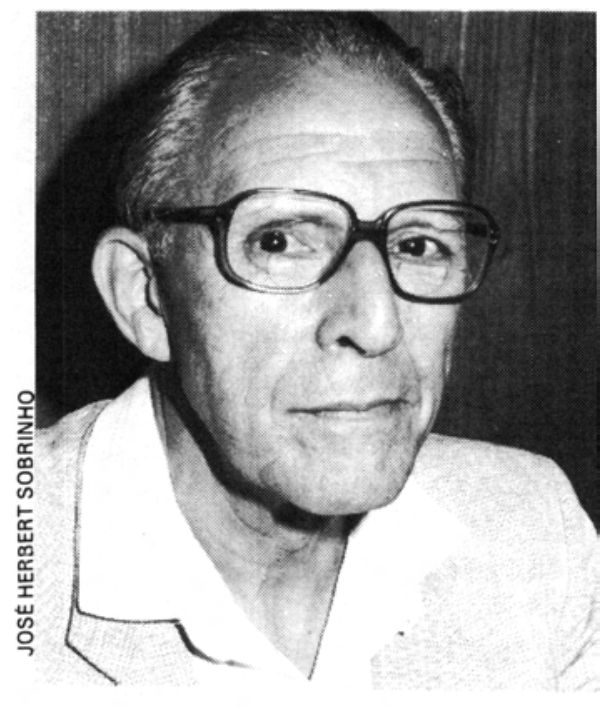

Federal de Uberlândia. 2 (1): 61 , julho de 1985.)

\section{Os interesses em conflito}

Rozestraten descreve, em entrevista, qual é o seu enfoque de Psicologia Social no entendimento da questão do trânsito, nos seguintes termos:

"O trânsito é um problema social. Em cada cruzamento, constatamos que os pedestres, os carros, os ônibus, as bicicletas etc. vão e vêm de diferentes direções. Em princípio, cada um deseja passar por esse cruzamento permanecendo ileso e deixando o outro passar também ileso. $\mathrm{Na}$ prática, a situação é mais complexa do que parece à primeira vista. $\mathrm{O}$ motorista quer fluidez do tráfego de veículos, o pedestre precisa de menor fluidez para que possa atravessar a rua e, por outro lado, o comerciante deseja que os fregueses possam estacionar em frente a sua loja. Portanto, os interesses das pessoas que participam do trânsito não são os mesmos, e entram necessariamente em conflito.

E mesmo os interesses das pessoas são variáveis conforme a situação. Por exemplo, uma pessoa quando é motorista vê o pedestre como estorvo no seu caminho, mas quando essa mesma pessoa torna-se pedestre vê o carro atrapalhando o seu caminho. Há uma ambivalência ou contradição no seu julgamento da situação, dependendo da posição que ele está assumindo. É um certo egoísmo no sentido de querer sempre em todas as situações a garantia de todos os direitos e o mínimo possível de deveres a serem cumpridos. Essa atitude interfere no trânsito para que não se tenha uma consciência de que o trânsito é um jogo social, envolvendo motoristas e pedestres, conforme regras definidas. A maioria imagina que pode fazer na hora as regras conforme as suas conveniências porque ele é mais importante do que as regras. 


\section{A impunidade \\ do mais forte}

$\mathrm{Na}$ nossa realidade, algumas pessoas têm mais direitos do que os outros. O filho do prefeito, o deputado, a mulher do governador e muitas outras pessoas acham que não precisam respeitar as regras porque são exceções às regras. Assim, reforça-se o desrespeito às regras, que depois se generaliza: se essas pessoas podem, por que eu, cidadão comum, também não posso? Em outros países, o processo é totalmente inverso ao nosso. Lembro que na Holanda um policial multou o príncipe Bernard e por isso foi condecorado. Quem vai ser condecorado no Brasil por multar o Presidente da República?

No Brasil, quem é o mais forte tem mais direitos, mas não deveria ter. Isso porque não há punição e nem fiscalização. Você pode atropelar e até matar alguém com o carro, e fica impune. No julgamento, são aceitos diversos argumentos de defesa: você não quis matar propositalmente, é réu primário etc.

Se houvesse uma fiscalização mais séria no trânsito, diminuiria sem dúvida o índice de acidentes. No Japão, eles conseguiram procedendo dessa maneira: multas altas e fiscalização para todo lado. Se você tem que pagar tanto porque o seu carro está mal estacionado, dentro de uma semana ninguém mais vai estacionar mal. Aí acaba ficando caro e o pessoal vai começar a pensar antes de levar multa.

É importante assegurar que o brasileiro coloque na cabeça que as leis de trânsito não são imposições autoritárias. Elas possuem uma vigência internacional e foram imaginadas para dar segurança a todos aqueles que participam do trânsito.

\section{As omissões da estatística oficial}

Os motoristas se impõem no trânsito pela força bruta, respaldados pela impunidade. Tanto é que a maior porcentagem de acidentes de trânsito é de atropelamento de pedestres. São 50 mil pessoas que morrem no trânsito todo ano. A estatística oficial é de 23 mil, mas refere-se somente àqueles que morrem no momento exato do acidente. Quem morre sendo transportado para o hospital, ou morre dois ou três meses após o aci-

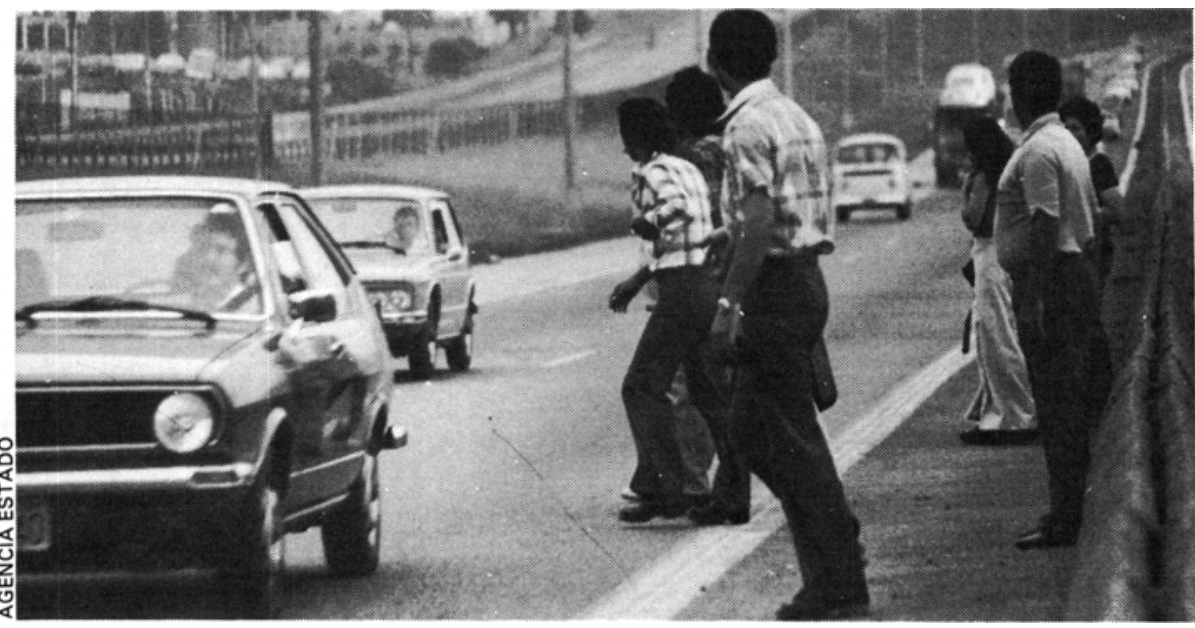

dente, não entra na estatística oficial. A mesma coisa acontece com todos os acidentes que não constam nos Boletins de Ocorrência, pois a polícia não foi chamada e tudo se resolveu informalmente entre os envolvidos.

O Boletim de Ocorrência não fornece informações suficientes sobre os acidentes. É preciso melhorar o Boletim de Ocorrência e dar um treinamento aos policiais para obterem mais dados, deixando de simplesmente acumular dados e números sem refletir a realidade. Deveria ser feita uma estatística que signifique alguma coisa de maneira muito mais diferenciada do que acontece hoje.

\section{Quem é o prejudicado num acidente?}

Constatamos que o acidente ainda é visto de modo muito genérico no Brasil. Quando há morte de duas pessoas ou quando um carro bate o párachoque num barranco, ambos os casos são considerados acidentes, mas são completamente diferentes entre si. Por isso,é preciso passar a fazer uma descrição mais minuciosa dos acidentes $\mathrm{e}$ dos envolvidos neles, abrangendo classe social, faixa etária, local etc. É um estudo de Psicologia Social que não foi feito ainda no Brasil.

Em termos de epidemiologia, o número de mortes de acidentes no trânsito é menor na realidade do que de mortes por doenças cardiovasculares. Entretanto, mais de $30 \%$ morrem nos acidentes de trânsito entre 18 e 30 anos, enquanto a maioria das vítimas de doenças cardiovasculares morre com 40 ou 50 anos normalmente. Mesmo que as vítimas de doenças cardiovasculares vivam até 70 anos, o número de anos de vida útil destes é bem menor em relação aos acidentados no trânsito que teriam mais 40 ou 50 anos de vida pela frente. São pessoas jovens em quem não somente os pais, como também a sociedade,investiram durante muito tempo. E, exatamente quando chegam à idade produtiva, perdem a chance de poder dar um retorno à sociedade por causa de um acidente de trânsito que pode ter acontecido por uma estupidez, distração ou ignorância.

\section{O trânsito como um bem social}

Precisamos abandonar a idéia de que o trânsito é um assunto só do DETRAN, do CONTRAN, do DNER. Os órgãos públicos colocam as placas de sinalização, marcam as ruas etc., mas quem faz o trânsito somos nós. Eles podem fazer o Código Nacional de Trânsito, mas quem obedece ou desobedece somos nós. Todos nós participamos do trânsito e nessa medida temos uma certa parcela de responsabilidade nisso.

Assim, o trânsito passa a ser visto como um bem social que pertence a todos. Todos têm direito ao trânsito, que não pertence somente a um ou a outro. Se alguém tem direito, também tem deveres em relação aos outros, e vice-versa. Teria que haver uma mudança de consciência de que o trânsito é de todos e para todos. Aí ocorreria uma tentativa de todo mundo permanecer vivo, alcançar seu destino e ninguém se ferir ou morrer. Seria um benefício para todos na sociedade e, nesse sentido, o trânsito deveria ser um exercício de convivência pacífica."

PSICOLOGIA, CIÊNCIA E PROFISSÃO - 23 